\title{
Rocuronium-sugammadex as an alternative to succinylcholine in electroconvulsive therapy
}

\author{
Saban Yalcin · Harun Aydogan · Hacer Serdaroglu
}

Received: 16 February 2011/ Accepted: 24 March 2011/Published online: 25 May 2011

(C) Japanese Society of Anesthesiologists 2011

To the Editor:

We read with great interest the article by Hoshi et al. [1] dealing with the recovery time from neuromuscular blockade induced by rocuronium combined with sugammadex versus succinylcholine during electroconvulsive therapy (ECT). Sugammadex has recently been introduced as a fast-acting, selective relaxant-binding agent that was specifically designed to rapidly reverse rocuroniuminduced neuromuscular blockade. This study is interesting for anesthesiologists who frequently encounter ECT sessions in their operating rooms and are waiting for safe agents that rapidly reverse neuromuscular blockade in this subgroup of patients. The authors revealed that recovery time of T1 to 10 and $90 \%$ in the rocuronium-sugammadex group was shorter than in the succinylcholine group although the difference was not statistically significant. The authors also revealed that seizure duration with succinylcholine ( $33 \pm 8 \mathrm{~s}$ ) was shorter than that with rocuroniumsugammadex (39 $\pm 4 \mathrm{~s})$ and reported a potential benefit of the use of rocuronium-sugammadex as an alternative to succinylcholine for muscle relaxation during ECT [1]. In our opinion, some points of this work are not sufficiently clear.

An answer to this letter to the editor is available at doi:10.1007/s00540-011-1165-9.

S. Yalcin $(\varangle) \cdot$ H. Aydogan

Department of Anesthesiology and Reanimation,

Harran University Medical Faculty,

Yenişehir Yerleşkesi, 63300 Şanlıurfa, Turkey

e-mail: sabanyalcin@yahoo.com

H. Serdaroglu

Department of Anesthesiology and Reanimation,

Guven Hospital, Ankara, Turkey
The authors reported a tendency to shorter time to recovery of $\mathrm{T} 1$ to 10 and $90 \%$ with rocuronium-sugammadex compared with succinylcholine but the difference was not statistically significant $(p=0.26, p=0.07$ ) and no significant differences in time to first spontaneous breath and eye opening in response to verbal commands were found with either muscle relaxant $(p=0.94$, $p=0.48)$. Absence of such a statistically significant difference might be because of the small sample size $(n=5$ in this clinical report) and/or increased variability of the time to recovery of $\mathrm{T} 1$ to 10 and $90 \%$ and the time to the first spontaneous breath between the first case and the remaining group. Not only the absence of statistically significant differences between the two medicationspossibly - for methodological reasons, but also the increased percentage of elderly ( $>65$ years) subjects $(2 / 5: 40 \%)$ weakens the findings of this report, because reversal of rocuronium neuromuscular blockade with sugammadex was found to be slightly slower in elderly patients [2].

Further large-scale prospective studies on sugammadex are mandatory, especially for patients with contraindications to the use of succinylcholine, although the cost of sugammadex may preclude such trials.

\section{References}

1. Hoshi H, Kadoi Y, Kamiyama J, Nishida A, Saito H, Taguchi M, Saito S. Use of rocuronium-sugammadex, an alternative to succinylcholine, as a muscle relaxant during electroconvulsive therapy. J Anesth. 2011;25:286-90.

2. McDonagh DL, Benedict PE, Kovac AL, Drover DR, Brister NW, Morte JB, Monk TG. Efficacy, safety, and pharmacokinetics of sugammadex for the reversal of rocuronium-induced neuromuscular blockade in elderly patients. Anesthesiology. 2011; 114:318-29. 